\title{
New Journal Decision Making
}

\author{
Janet D. Bailey
}

This paper will discuss the steps through which a publisher proceeds in making the decision as to whether to publish a new research journal and some of the considerations involved in establishing prices for a new journal.

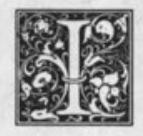

n general, the decision to launch a new journal has become more difficult in recent years because of changes in the economic environment in which publishers operate. For example, in 1987 Elsevier Publishing Co. launched five new journals. Significantly, during that year the company declined to publish about ten new journals that were considered and researched quite seriously. In addition, the publishing staff corresponded with many individuals with ideas for new journals. Of the five new journals Elsevier did start up, three were sponsored by biomedical societies and therefore would likely have been started even had Elsevier chosen not to publish them. Just as perhaps 80 percent of papers that are rejected by one journal are probably published somewhere eventually, many of the journal proposals that one publisher rejects are eventually accepted by another publishing company. Following is a description of the general process by which new journal proposals flow from the idea to the launch stage.

\section{PROPOSALS FOR NEW JOURNALS}

Ideas for new publications are generated from three main sources. First, a researcher may perceive a need for a new journal on a topic of personal interest and approach a publisher with the suggestion to launch this new journal with the researcher at the helm. A second source is scientific societies that may have been too small to publish their own journal but that have grown large enough to provide a sufficient author pool. In this case, the publisher might be approached by an ad hoc publications committee of the society. The third source of new ideas is the company's editorial staff. They obtain publication ideas by visiting research institutions and talking with scientists and scholars about information and publication needs, and by attending conferences to keep abreast of developing trends.

Ideas for new research journals may be categorized in two ways. The first type is prompted by growth of a field such that discrete subfields identify themselves as large enough to attract enough papers to feed a journal. An example of this is a journal idea that was eventually rejected. In this case, the colleagues of the editor of a journal on cancer cell growth suggested starting a journal on solid tumors. The proponents of the journal idea noted the importance of the subfield and the fact that they had a list of several thousand researchers actively involved in this area, who read a monthly newsletter they produced on this subject.

Janet D. Bailey is Associate Publishing Director, Elsevier Science Publishing Company, New York. This paper was presented May 3, 1988, at a meeting of the collection development librarians at Columbia University Libraries, New York. 
When approached with such proposals, the publisher begins its research by talking to authorities in the field to test the idea's strength. The staff editors then examine the existing literature to determine the prevalence of papers on the subject, what journals the existing papers reference, how many pages those journals have, and whether the publication lag times represent a threat to the efficient and timely dissemination of scientific information. After competitive analysis, a market research questionnaire is mailed to determine from investigators whether there is a perceived need among the scientific community for such a journal. One aspect of this is the publisher's very real concern with whether the proposed journal will receive enough papers. Editors investigate where the targeted researchers are currently publishing their work and whether there is room for a journal on this more highly targeted area. In the case of the solid tumor idea, the publisher decided that the research community did not yet need a specialized journal for the publication of solid tumor papers.

A second type of idea for a new journal is the perceived need to compile research on various aspects of a single subject. In this case, rather than breaking down a subject into smaller parts, a subject is considered from the point of view of various specialties, the idea being to gather in one place the variety of papers on a single subject that may be dispersed throughout many journals.

An example of a journal that Elsevier launched that fits into this category is $\mathrm{Ar}$ thritis Care and Research. The idea for this journal was presented by a committee of the Arthritis Health Professions Association of The Arthritis Foundation. This group consists of 2,000-3,000 therapists, nurses, and allied health professionals who work specifically with arthritis patients. Their group had grown quickly over the last few years, and they saw a need for a journal devoted to clinical research on the care of arthritis patients. Such a journal, it was reasoned, would focus on research at a different level from that of medical research publications. As well, it would be more targeted to arthritis than any of the existing therapy journals. The association did its homework. It polled its membership to determine how many papers they were publishing annually in this area. It was important to ensure that there would be enough manuscripts from their own membership to seed the growth of a journal until it could attract papers from outside the group. Upon completion of its research, the association presented its proposal to the publisher.

\section{JOURNAL SUBSCRIBERS: AUTHOR, RESEARCHER, AND LIBRARIAN}

This example of the launching of a new journal touches on the very critical subject of the author as customer. Publishers realize that a journal needs to fill a real need in order to succeed. This means that the journal not only must attract subscribers, but also must generate editorial respect, which translates into authors who will submit papers, researchers who will read them, and librarians who will endeavor to add them to their collections. If the journal does not fill a research or scientific need, it cannot be successful. Authors and subscribers may not be the same person, since librarians are usually the actual purchaser of the journal. If authors do not read, cite, or contribute to the journal, no one will subscribe. Librarians, who act as information gatekeepers, will not maintain subscriptions to journals for which authors and researchers do not exhibit a need.

\section{"Journal publishers pay attention to measures such as the Institute for Sci- entific Information's Science Cita- tion Index impact factor, as well as accessibility through key indexing and abstracting services.'}

And so the competition analysis must identify a need for the publication by both authors and readers in order for a company to decide to commit its resources to launching a new journal. The existence of a sufficient author pool usually indicates a sufficient subscriber pool. A journal really 
functions as an archive for the research of a field. For this reason, journal publishers pay attention to measures such as the Institute for Scientific Information's Science Citation Index impact factor, as well as accessibility through key indexing and abstracting services.

\section{CRITERIA FOR NEW JOURNALS}

In sum, what are the reasons for starting a new journal?

From the editorial point of view, there may be no journal that covers the proposed topic in sufficient detail. A subfield may have developed. Alternatively, there may be no journal that brings together papers on all aspects of a given subject. The current journals in a field may be so beleagured by submissions that the delay between submission and publishing is inordinate, impeding the research dissemination process. A journal may have grown so large that it can no longer be handled by a single editor and needs to be split into discrete subfields to be manageable. Ancillary to these considerations is the availability of high-quality scientists to serve on the editorial board. Behind all of this is the publisher's concern with the quality of the anticipated product. Because the company's imprint appears on its journals, it will try to ensure that new journals will be of the highest quality.

From the company point of view, even if a new idea is determined to be a good one, a journal will only be launched if it complies with the firm's internal criteria. Important among these are whether the proposed journal fits within the subject areas in which the company currently publishes or has identified as areas into which the company plans to expand. Clustering of subject areas is important to maximize the expertise of staff. Financially, a company can support its marketing and customerservice efforts more effectively by publishing within specified subject areas.

Another way publishers weigh proposals is by determining how the level of the material fits with its current output. For example, one publisher may publish very little at the undergraduate level, while another may concentrate its edito- rial resources and sales efforts there. A publisher evaluates the market from the standpoint of who the purchaser is, or where the money comes from to purchase the journal. For example, many journals are designed primarily for the library market, either in the United States or worldwide, and others are designed mainly for the professional or industrial market. There is, of course, always potential for overlap in such market definitions, but the emphasis may vary.

The market for a journal must be evaluated in a fair amount of detail because the library or industrial markets are, in reality, groupings of discrete segments. For example, a biomedical research journal's principal market may be the library. But what does this mean? It may include 2,000 medical libraries worldwide, or as many as 5,000 , depending on the applicability of the research. It may be limited to 125 large pharmaceutical companies, or it may extend to 2,000 or more worldwide. Business or technology journals may be of interest to only graduate school libraries or extend to all four-year colleges and universities, or appeal to junior and community college library needs. They may be useful to thousands of companies in the United States or, if the subject matter is international, worldwide. The governing criterion is always the extent of application of the information provided.

\section{FINANCIAL PROJECTIONS}

Once a proposal has been examined from the editorial side, it is subjected to financial projections. A hypothetical, hopefully realistic, five-year profit-and-loss statement is generated. To build this projection, every line item that needs to be considered in publishing a journal is estimated. This analysis begins by considering the number of pages that are to be published each year. Most often a journal is launched with quarterly or bimonthly issues of, perhaps, eighty or ninety-six pages. The level of manuscript flow is then estimated for the five years of the projection in order to project growth of issues. The next step is to project the potential growth in subscribers over the five years, the anticipated subscription price, 
and associated marketing cost. The cost of promoting even a moderately sized new journal, for example, can be in excess of $\$ 20,000$ in each of the first few years of publication. Projections such as these require some understanding of the market and of likely growth of the specialty field and its research activity. (Journals can only reflect, and not create, the actual research in a field).

From these calculations derive production, editorial, fulfillment, mailing, and postage costs. Even the cost of the editorial office must be included. While the editor-in-chief usually earns a modest stipend and the publisher provides some payment to the editor's institution to help pay for office costs, the editorial board more often serves without pay, earning only professional fulfillment and, perhaps, an annual editorial board lunch or dinner in compensation for their service. (While its merits are oft-debated, peer review has as its goal the assurance of publication of valid, significant, and unduplicated research.) Income from the sale of author reprints is estimated along with the attendant costs. The departmental costs for internal management of the journal are estimated, and a share of the corporate overhead costs is assigned. Some examples of these kinds of costs are those of computer input of subscriber information, customer-service personnel, in-house editor/author negotiations, production department purchasing of raw materials and contracting with vendors, and accounts receivable staff.

The acquisitions department works with the editorial office in the early years of a new journal to define the specific aims and scope of the journal, make recommendations for sections to structure the publication, and help initiate and sustain manuscript flow. Acquisitions also works with the scientific editor and the design staff to develop the page and cover design.

Having projected anticipated costs, prices for the journal over the planning period are estimated, and the financial model is built. The price of the journal in the first year is set to be consistent with those for typical journals in similar subject fields, for similar markets, and of similar size. For each year, anticipated cost increases due to inflation and growth in number of issues and pages are computed. Price increases are dependent to a large degree on the number of pages published. Each year a budget is established that sets the number of pages upon which the costs and prices are based. If for some reason more pages are published than planned in any year, the financial performance of the journal is negatively affected because of the extra costs resulting from those additional pages. In an established, perhaps profitable, journal, this effect may be less damaging because there may be sufficient income to offset some of the costs, although profit level will still be affected. In a young, struggling journal, though, such an effect is likely to eliminate any potential for profit at all within the first few years. Because of growing research needs, editors frequently seek permission to publish more pages. To counter this trend, publishers work with the editors to increase their rejection rate or to limit the scope of the journal to only certain categories of papers. For example, a decision might be made to eliminate case report papers in order to concentrate on original research.

One crucial component of costs is inflation. Costs incurred in the industrial sector, including publishing companies, are different from those included in the Consumer Price Index. Two significant examples that experienced particularly steep increases in 1988 are paper stock and postage. Prices of publication paper stock increased by over 30 percent during the year. Paper stock can represent 30 to 40 percent of the manufacturing costs of a journal, which in turn compose 20 to 35 percent of a journal's costs. Thus, an increase of 30 percent in paper cost can translate into an overall cost increase of nearly 5 percent for a journal. Postage costs increased in the United States in 1988. Second-class rates, under which most journals are mailed, increased an average of 18 percent. Representing between 5 and 10 percent of total costs, postage expenses have a material effect on a journal's profitability. 
Growth projections have become more difficult in the last few years because of the change in the journal marketplace. The tens of thousands of existing journals leave little room for new ones. Comparisons of growth projections for new journals launched in the 1960 s and 1970 s with those launched in the $1980 \mathrm{~s}$ indicate that projections are much more modest as journals are launched in smaller, more targeted subfields that represent smaller markets. While direct comparisons are difficult because of intangible variables such as quality and subject area, even a highquality journal in a good-sized area may today expect to reach only 70 to 80 percent of the number of subscribers as a similar journal started ten years ago. For smaller journals, with less certain editorial quality, the saturation may be lower.

The resources a publisher must commit to building a journal have not decreased, though. Both staff and financial resources are required in sufficient amount to give a journal a fair opportunity for survival. Many publishers commit to three to five years of publication to determine a journal's potential. During, and even after, that period most publishers take every step they can to save an ailing journal.

Such corrective efforts are important for two related reasons. First, publishers realize that establishing a new journal places a strain on the resources of a library unless that journal fulfills a distinct market need. Because every effort is made to ensure that the journal will be needed before it is introduced, publishers believe that they are building a trust by those who enter a subscription, and who then establish records, procedures, and space for receipt and storage of the journal. Therefore, the decision to discontinue a new or existing journal is made only after careful deliberation and after attempting to save it by a variety of measures. Second, of course, is the fact that starting a new journal commits scarce staff and fiscal resources. Discontinuing a journal ceases all hope of recovering the significant investment that has been made.

Publishers establish benchmarks by which to measure the success or failure of a new journal for each year. Among those criteria is the stipulation that the total investment in a new journal be recovered by a predetermined year. This investment can exceed $\$ 150,000$, and it is rare for it to be recouped in fewer than five years of publication. In fact, a new journal does not usually break even on an annual basis on direct out-of-pocket costs until after the second year. It makes sense, therefore, that publishers are vitally concerned that new product ideas be subjected to serious analysis before giving the green light to them.

Once a journal has recouped its investment, it is hoped that it will begin to produce a measure of profit which the company can then earmark to research new, cost-saving production technologies and to launch new journals.

\section{CARE FOR THE AILING JOURNAL}

While there is, of course, nothing that can be done if no real market exists for a journal, publishers will attempt to take several types of corrective action to enhance a journal's potential for survival. Manuscript flow can be encouraged. There are journals for which research has indicated a need and for which customers have entered subscriptions, thus demonstrating a market need, but to which papers, or the right kind of papers, are not attracted. One pediatric journal started seven years ago experienced this problem-it initially had difficulty attracting the type of clinical paper for which it was designed. By careful management of the rejection rate, the journal was able to add quality manuscripts just as effectively as it had added subscriptions. This unique journal is only now reaching its potential, and its investment has not yet been recovered. A similar example is a systems journal that Elsevier started about four years ago. It was chronically late because of difficulty in attracting manuscripts. It had a healthy renewal rate, however, which indicated subscriber interest. This level of interest impelled the company to work to sustain the journal. Research interest paralleled subscriber interest through maintenance of good quality, and the journal is now performing well. 
The publishing industry is keenly aware of the disruption to the information market that is caused by fractionalization of journals. Every publisher can cite examples of efforts at consolidation in order to minimize such fractionalization. One example is that of a very promising small medical journal published by Elsevier, growing in size and in subscribers, confronted with a small but expanding society expressing a firm commitment to launching its own journal. Not wishing to further fragment the market, the company reached an agreement to convert the journal it owned into a new journal owned by the society and published by Elsevier. While it was recognized that a compromise such as this would cause some confusion with library record keeping, the advantages to librarians, the scientific community, and the publisher by avoiding publishing an additional journal outweighed any initial confusion.

"While conducting the analyses related to introducing a new journal, publishers retain the spectre of tight library budgets, which are at odds with the growing needs of researchers for timely access to scientific developments."

\section{THE RESEARCH \\ PUBLISHING ENVIRONMENT}

Most of the factors discussed here are practical considerations that determine everyday decisions. Publishers are fully cognizant of the fact that these daily publishing decisions have an enormous impact on the scientific and information community. They therefore believe themselves to be a partner in that community and think about the worldwide effect of publishing policy on the company level. While conducting the analyses related to introducing a new journal, publishers retain the spectre of tight library budgets, which are at odds with the growing needs of researchers for timely access to scientific developments. Publishers participate in dialogue within the professional community about the ethics of dual publication and scientific validity to try to prevent the clogging of information channels with invalid or unnecessary information. Particularly among medical media, publishers compete with non-peer-reviewed journal media that have different cost structures that allow subsidization of prices by the advertising community. Efforts at protecting copyright from international piracy help keep subscription prices down. At the same time publishers establish structures to try to respond quickly to appropriate permissions requests and to ensure access to needed scientific and business information. Publishers consider the potential impact over the long term of resource-sharing and electronic publishing and their effect on pricing. Editors and publishers debate the same question that librarians ponder, that is, whether the printed journal will even exist in twenty years as a subscription product. Even the effect of government policy on transborder information flow is a consideration in determining publishing policy.

Questions such as these may seem so theoretical as to be incidental to the publishing process. However, a journal is launched with the expectation that it will continue for decades, and, of course, many current journals have existed ic. well over twenty-five years. Consequently, concerns about the direction of scholarly information publishing are not insignificant.

In conclusion, there is one seemingly small point that infuses the editorial environment in which new publishing products are developed. After all the editorial and competitive analyses, objective financial calculations, and difficult decisions, the excitement generated within the publishing house about a new product is contagious. There is a lot of care and personal enthusiasm that goes into building a new jourial. As a result, a new journal idea must have merit to generate the commitment to publish. Journal ideas die for lack of a staff advocate. This is a littleconsidered but important decision point along the path from initial idea to successful journal. 


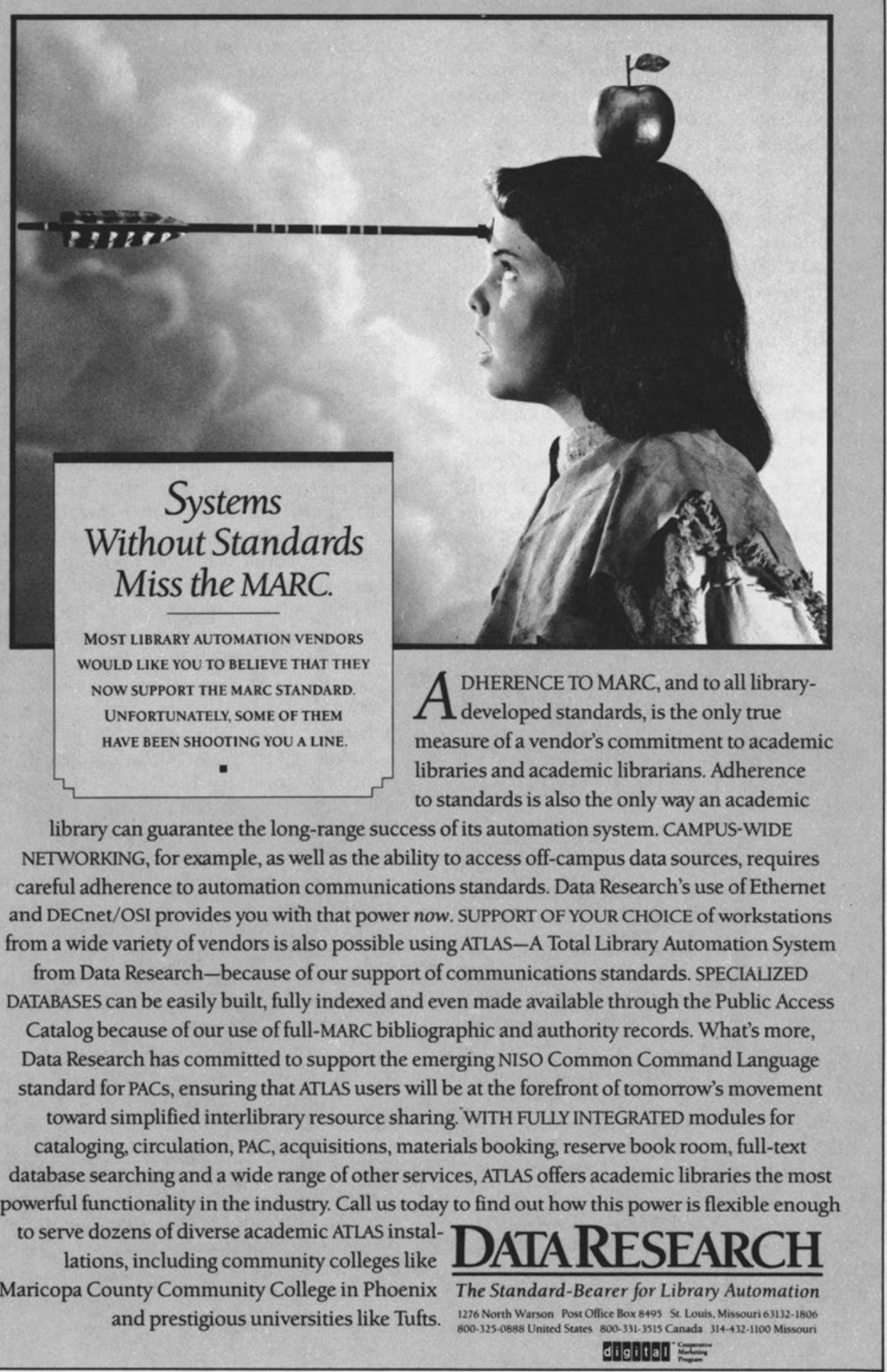

